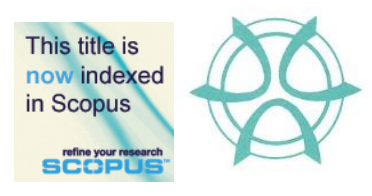

PLANNING MALAYSIA:

Journal of the Malaysian Institute of Planners

VOLUME 15 ISSUE 4 (2017), Page 105 - 114

\title{
PUBLIC PERCEPTION ON TRAFFIC POLLUTION IN FEDERAL TERRITORY OF KUALA LUMPUR, MALAYSIA
}

\author{
Siti Haslina Mohd Shafie ${ }^{1}, \&$ Mastura Mahmud ${ }^{2}$ \\ ${ }^{1,2}$ Faculty of Social Sciences and Humanities \\ UNIVERSITI KEBANGSAAN MALAYSIA
}

\begin{abstract}
Increasing pollutant emission from vehicles and traffic jams is a serious environmental problem in major cities. This study is focused on the level of public perception and awareness on traffic pollution in the capital city of the Federal Territory of Kuala Lumpur, Malaysia. Analytical tools such as descriptive analysis were applied to investigate the percentage of public perception and awareness towards traffic pollution and identify factors that influence this problem. Results showed that almost all respondents (99\%) were very sensitive and were aware on traffic pollution regarding the physical, nonphysical factors and the health effect. Most respondents indicated that emissions from exhaust after switching on was the major contributor of air pollution. In terms of health, respondents perceived that traffic pollution impacted health and a cause of illness. Most respondents agreed with initiatives that provide incentives for public transport usage so that emission from vehicles can be reduced significantly.
\end{abstract}

Keyword: Traffic pollution, public perception, descriptive analysis

Date Received: $24^{\text {th }}$ July 2017

Date of Acceptance: $6^{\text {th }}$ November 2017

${ }^{1}$ Postgraduate at Faculty of Social Sciences and Humanities. Email: sitihaslina87@gmail.com 
Siti Haslina Mohd Shafie, \& Mastura Mahmud

Public Perception On Traffic Pollution in Federal Territory of Kuala Lumpur, Malaysia

\section{INTRODUCTION}

Traffic was the main source of ground level pollution in the urban environment and undesirable consequences to the human health. Gaseous and particulate sources such as carbon dioxide $\left(\mathrm{CO}_{2}\right)$, carbon monoxide $(\mathrm{CO})$, oxides of nitrogen (NOx), lead compounds, hydrocarbons (HC's), sulphur dioxide $\left(\mathrm{SO}_{2}\right)$, suspended particles $\left(\mathrm{PM}_{10}\right)$, water vapour, nitrogen oxides $\left(\mathrm{NO}_{2}\right)$ and ozone are emitted by vehicles. In Malaysia, the $\mathrm{PM}_{10}$ daily concentrations measured were above the 50 $\mu \mathrm{gm}^{-3}$ criteria limit set by the World Health Organization Air Quality Guidelines for most of the month and exceeded the 24-h Recommended Malaysian Air

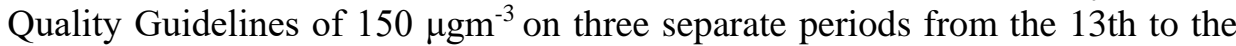
30th August 2004 (Mahmud 2013).

Traffic emissions can cause serious public health impact within the urban environment. Researches around the world estimated that up to 1.6 billion people globally were exposed to increased risk of cardiovascular diseases, respiratory illnesses, cancers, mortality (Brook et al., 2004; Pope \& Dockery, 2006; Badland $\&$ Duncan 2009), heart attacks, respiratory diseases and lung cancer (Cunningham, Cunningham \& Saigo, 2005; Mabahwi, Ling \& Omar, 2015), chronic coughing and susceptibility to infections, bronchial inflammations, allergic reactions, and irritation of the mucous membranes of the eyes and nose. All these studies implicate that air pollution must be reduced (Enger \& Smith, 2000).

The serious adverse health effects of traffic pollution in the urban environment have contributed in creating public awareness and perception in term of mitigation processes and management strategies (Mabahwi, Ling \& Omar, 2015). This perception is related with the psychological processes that people are more likely to perceive environmental problems when they can hear (noise), see (smoke), smell or feel, and the media is a dominant source that has a social amplification effect and influence public perceptions and attitudes (Gatersleben \& Uzzell 2000). Therefore, research about the relationship between individual perception and attitude towards traffic pollution focusing on the socioeconomic factors around the world clearly found that most people are highly aware of the meaning of air pollution (Elosta, Leksono \& Purnomo, 2013; Byrd, VanDerslie \& Peterson, 1997; Badland \& Duncan, 2009; Gregory et al., 2008; Tonne et al., 2008).

\section{LITERATURE REVIEW}

Emission from vehicles caused serious health effects to human depending on the level of exposure, pollutant concentration and individual health status (WHO, 2000; Han \& Naeher 2006). Traffic related air pollution remains a key target for public-health action in Europe. About half of more than 40,000 cases caused by air pollution was attributed to motorised traffic, accounting more than 25,000 new cases of chronic bronchitis (adults); more than 290,000 episodes of bronchitis 
PLANNING MALAYSIA

(children); more than 0.5 million asthma attacks; and more than 16 million person days of restricted activities (Künzli et al., 2000). Bayer-Oglesby et al. (2006) provided the strong confirmation that living near busy streets lead to adverse respiratory health effects. This is agreed by Garshick et al. (2003), who show that men living within 50 metres of a major roadway were more likely to report persistent wheeze compared with those living more than 400 metres away of heavily trafficked roads.

Katsoulis et al. (2014) indicate that long-term exposure to traffic related air pollution has an impact on cardiovascular disease (CVD) and ischemic heart disease (IHD) morbidity, particularly among women and younger people. Chen, Jackson and Bina (2009) explored the geographic pattern of adenocarcinoma incidence rates of the lung (ADL) and its relation to motor vehicle density, and found that risks accounted at $136 \%$ and $68 \%$ higher for ADL and squamous cell carcinoma, respectively, for male residents living in areas with 937 motor vehicles per square mile, compared with those living in areas with about one motor vehicle per square mile. However, for allergic symptoms and illnesses like asthma, allergic rhinitis, atopic dermatitis, wheeze, and allergic sensitization, less consistent results have been found (Heinrich \& Wichmann 2004). Traffic pollution are also associated with emergency hospital admissions for cardiorespiratory diseases especially among those living in areas with the highest socioeconomic deprivation (Halonen et al., 2016).

Socioeconomic background also related to differences of perception, knowledge and awareness among respondents such as age, gender, education and employment. The domination of males on the knowledge and information related to traffic pollution has been proved by other studies such as Alvinsyah, Soehodho and Nainggolan (2005) that indicated strong influence and relationship between gender and age factors with air pollution. Studies also shown that males have stronger preference to drive and are less likely to shift to public transport than women (Morikawa et al., 2003; Chee \& Fernandes, 2013).

Meanwhile, age factor also influenced the perceptions and opinions about traffic pollution. Elderly group (above 60 years) recorded very low knowledge and information about traffic pollution, and that more elderly men than women drive themselves (Chang \& Wu, 2005). Other socio-economic factors related with air pollution are education, income, household sizes and license ownership. Therefore, this study is focussed on analysing the perception, opinion and awareness among the public in the Federal Territory of Kuala Lumpur on details of physical and ambient environment factors, health effects and causes, besides the strategies and initiatives to control and reduce traffic pollution.

\section{METHODOLOGY}

This study employed questionnaire survey as the method of primary data collection. Respondent were randomly sampled from several areas in Kuala 
Siti Haslina Mohd Shafie, \& Mastura Mahmud

Public Perception On Traffic Pollution in Federal Territory of Kuala Lumpur, Malaysia

Lumpur, namely Manjalara, Wangsa Maju-Maluri, Bandar Tun Razak, Sungai Besi, Damansara-Penchala, and Kuala Lumpur City Centre. The questionnaire was developed based on operational definitions for each construct based on findings of previous studies. The data obtained from the survey were analysed using IBM SPSS version 22. Descriptive analysis were used to describe information about the background and analysis of the samples to provide an initial overview of the respondents' profile like gender, race, age, education, occupation, income and place of residence, as well as their perceptions of traffic pollution.

\section{RESULTS AND DISCUSSION}

\section{Demographic Profile of Respondents}

Analyses of the data obtained from the survey show that the number of respondents was dominated by men (57\%). Majority of the respondents were Malays (72\%), followed by Indians (16\%), Chinese (9.5\%) and other races $(2.5 \%)$. Adults formed the highest number of respondents at $69 \%$ and most respondents $(48 \%)$ attained secondary school education. In terms of employment, $47 \%$ of the respondents worked in the private sector, $32 \%$ were self-employed and the rest were civil servants. 37\% of the respondents earned less than RM2,000 monthly, 33\% earned between RM2,000 to RM5,000.

\section{Public Perception and Awareness on the Traffic Pollution}

The focus of the survey was to evaluate public perception and awareness on the sources of traffic pollution, the health effects of the pollution and the strategies to mitigate the pollution. In terms of the sources of traffic pollution, majority $(63.5 \%)$ of the respondents agreed that the problem of traffic pollution was 'emission from the engine after switch on' (Figure 1). They also agreed that 'emission from the fuel's evaporation process' $(62.5 \%)$ also contributed to traffic pollution (Figure 2). Moreover, respondents (20.5\%) did not agree that 'emissions from vehicle moving and road surface' automatically influenced the vehicle's emission. They were also unsure that 'emission from the fuel's evaporation process' and 'emission from the engine thermal operation' $(26 \%)$ significantly impacted the level of traffic pollution.

The respondents $(71 \%)$ perceived that 'wind speed' is the primary cause of increasing the concentration of traffic pollutants but were not aware of the 'green surface in the city' (17\%). Meanwhile, small number of respondents (22\%) were also confused on how 'topography' can also affect traffic pollution (Figure 2). 
PLANNING MALAYSIA

Journal of the Malaysia Institute of Planners (2017)

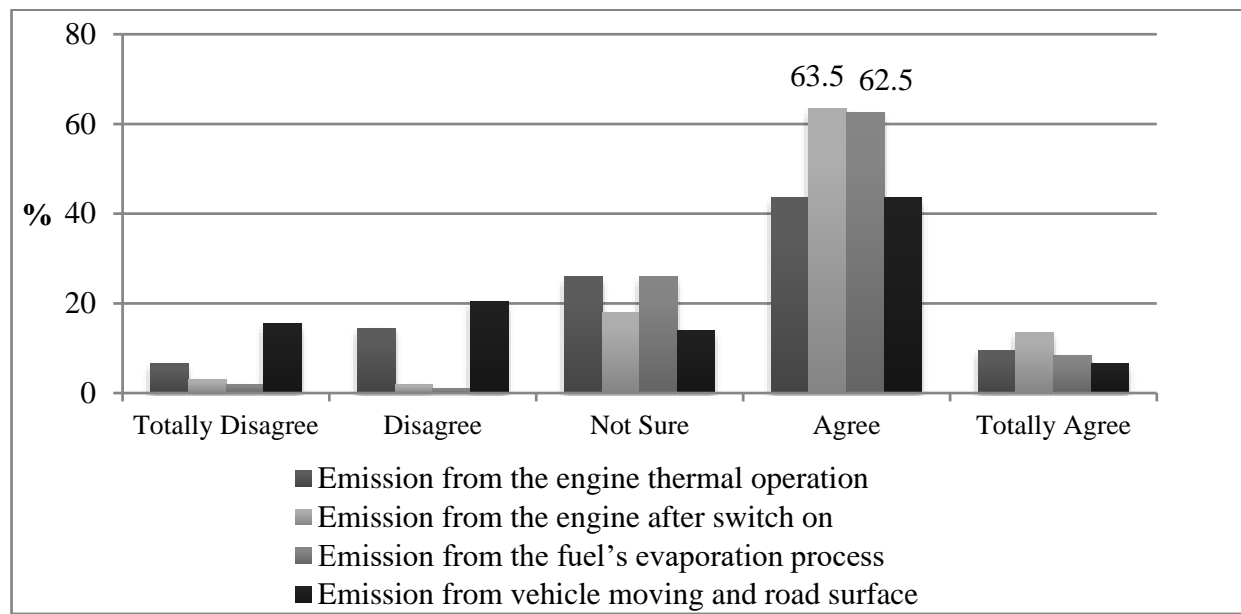

Figure 1 Physical factors of motor vehicles and how individuals exposed to traffic pollutants

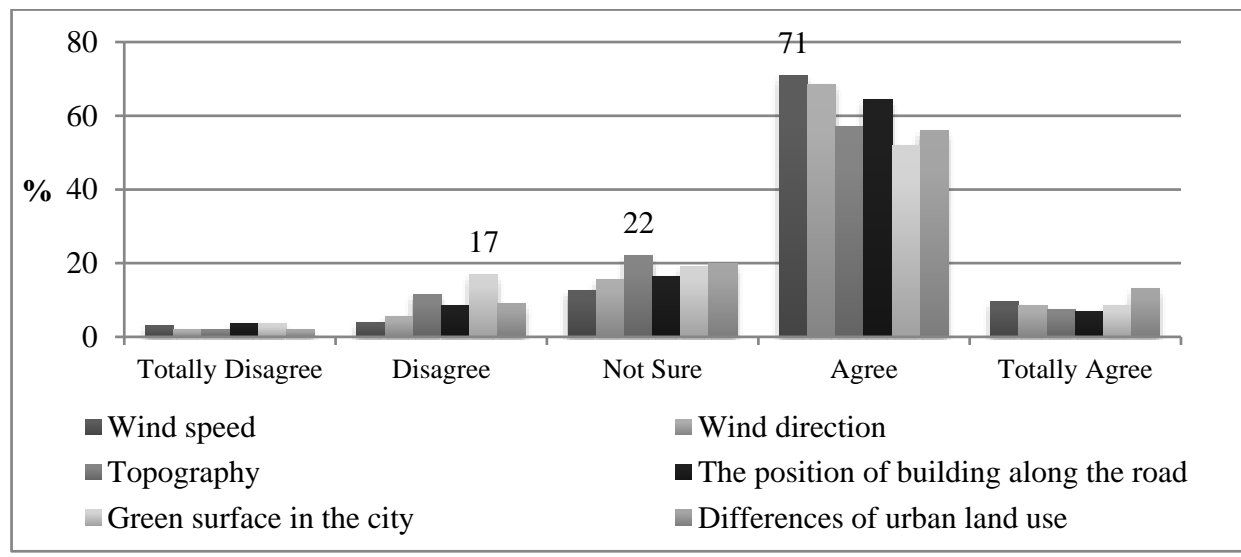

Figure 2 Ambient environment factors

Respondents were also asked of their perceptions on health effects of traffic pollution. Highest percentage of respondent (75\%) agreed that 'pneumonia' is an effect of traffic pollution. This is followed by 'asthma', where $70.5 \%$ of respondents perceived it to be an illness related to traffic pollution (Figure 3). In terms of factors, most respondents perceived that 'current health status' is the major cause of illnesses (82\%) related to traffic pollution. Meanwhile, $77 \%$ and $76 \%$ of the respondents agreed that 'age' and 'frequency and duration of exposure' exacerbated illnesses related to traffic pollution (Figure 4). 
Siti Haslina Mohd Shafie, \& Mastura Mahmud

Public Perception On Traffic Pollution in Federal Territory of Kuala Lumpur, Malaysia

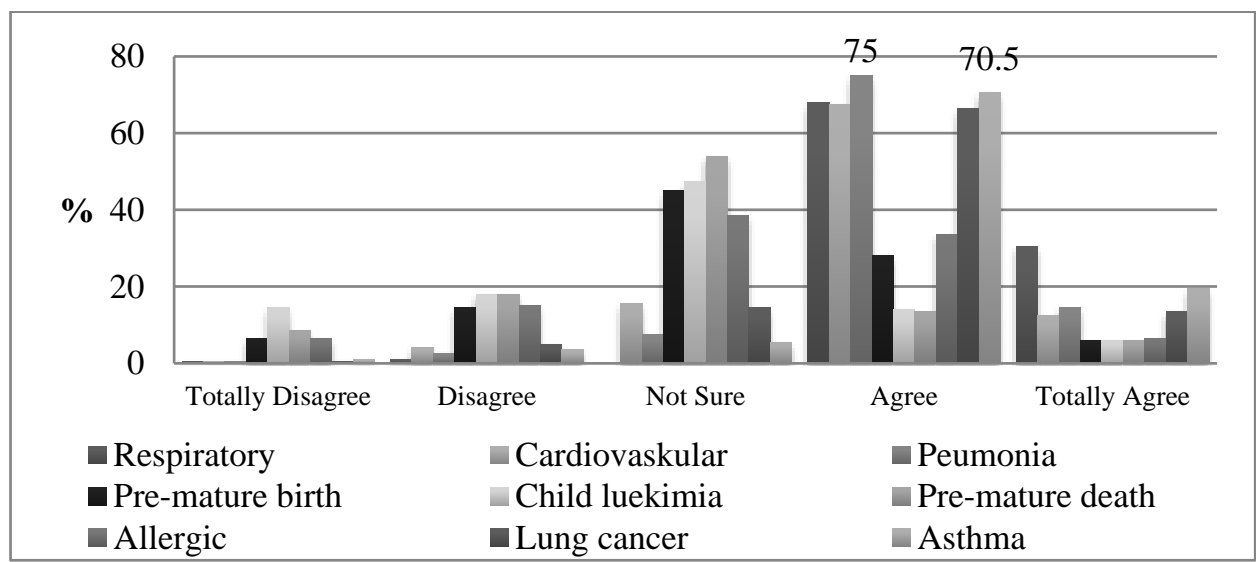

Figure 3: Health effect of traffic pollution

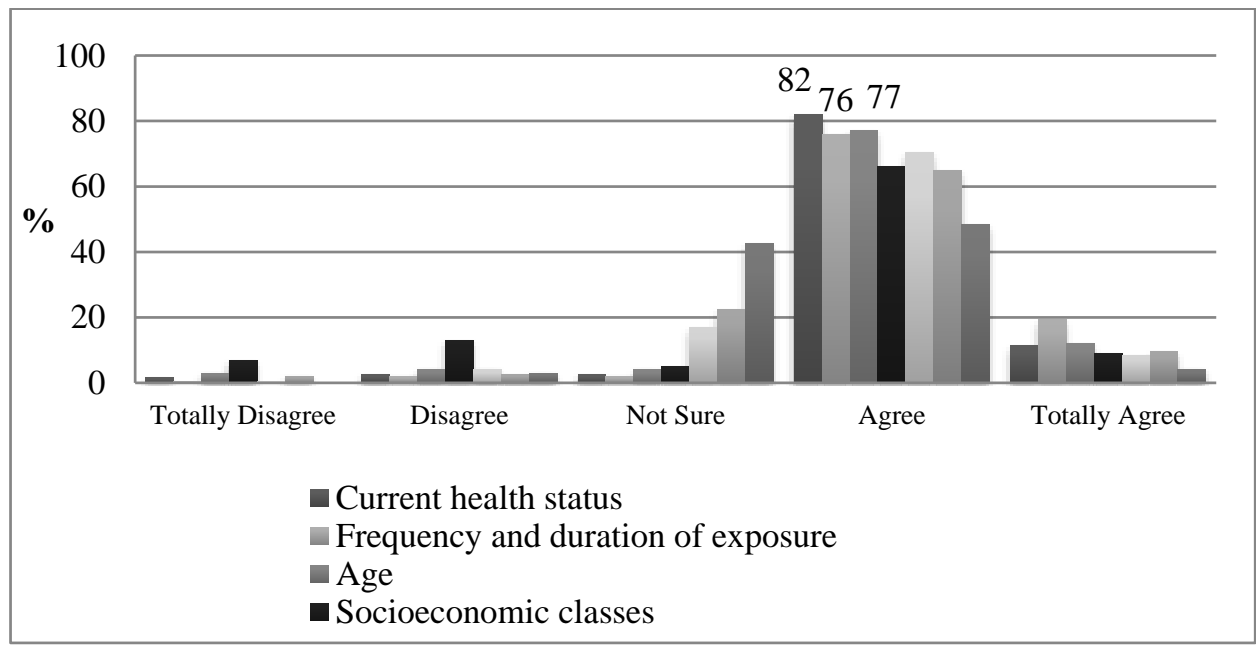

Figure 4: Factors of health effects

In terms of measures to mitigate traffic pollution, Figure 5 shows that most respondents $(72 \%)$ agreed that 'providing incentives to public transport users' would be one of the main measures to reduce traffic pollution. Other measures which were agreed to by majority of the respondents were 'use public transport' (71\%), 'using hybrid vehicle' $(70.5 \%)$ and 'using electric vehicle' $(68.5 \%)$. However, respondents strongly disagreed and disagreed with 'increasing fuel prices' $(69 \%)$ and 'charge motorist during busy times' $(84 \%)$ as measures to reduce traffic pollution because these would further contribute to the higher cost of living. 


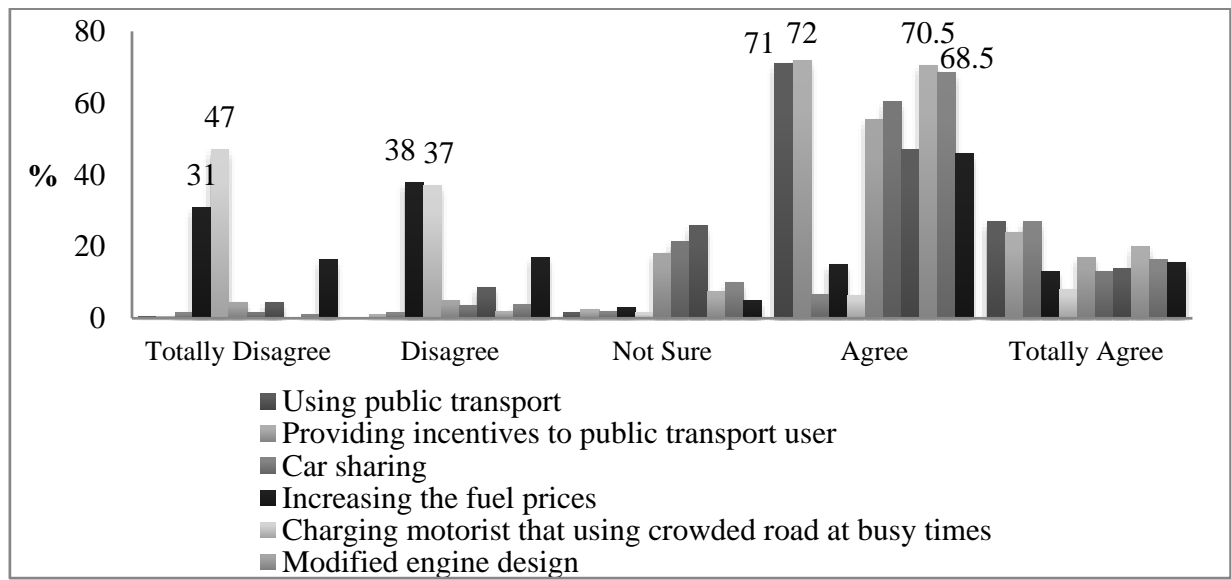

Figure 5 Initiatives and incentives to control and reduce traffic pollution

From the results of the analyses, it can be deduced that most of the respondents knew and were aware of the traffic pollution problems in the study area. The public knowledge was identified as a major influence to the understanding about sources of traffic pollution, drivers' behaviour change and implementation of effective health promotion strategies and policy to control negative impacts of traffic pollution. In spite of the public perception, risk perception is influenced by a mixture of environmental and contextual factors and is crucial to the public response in mitigating risks and can cause effects on the way plans are made, such as seeing or smelling exhaust fumes or seeing traffic congestion that led to a heightened perceived risk (Badland \& Duncan, 2009).

\section{RECOMMENDATION}

Traffic pollution in Kuala Lumpur is identified as a serious environmental problem to public health, ecosystems and climate change. Therefore, various acts, policies and strategies from the government and stakeholders can be implemented to tackle, control and reduce traffic emission to the minimum level and pave the way towards sustainable environment.

\section{Integrating Environmental Concerns into Economic Decisions}

National sustainable development strategies must be developed and followed up with evaluation and monitoring procedures that have been established at the regional level. In the field of taxation, the restructuring of the car registration tax and annual circulation tax on the basis of $\mathrm{CO}_{2}$ emissions, some strategies can be implemented such as internalising externalities and implementing the polluter pays and user pays principles to integrate further environmental concerns into transport policies. Policies and strategies that give special attention to the use of 
Siti Haslina Mohd Shafie, \& Mastura Mahmud

Public Perception On Traffic Pollution in Federal Territory of Kuala Lumpur, Malaysia

specific economic instruments (green certificates to promote renewable energy, tax on NOx emissions, road pricing) can also be formulated.

\section{Integration of Environmental and Social Decisions}

Local governments should be encouraged to invest in public outreach activities and programmes to build strong public awareness of regional and local air quality issues. Local governments can conduct meetings to hear citizen concerns regarding air quality and environmental justice. Residents should also be informed of proposed large development projects, and updated on cumulative air quality impacts and evaluate various options to reduce health impacts from exposure to air pollution. Collaboration with local school can help to increase student awareness of air pollution and health effects. These can be in the form of distributing air quality information, brochures and fact sheets on the health effects of air pollution. Additionally, collaboration can also be towards developing air quality curricula for students.

Stronger public transport policies is also needed. Public transport emits less pollution than private cars. Public transport has the biggest potential to become a very sustainable and clean mode of transport that provides mobility for all citizens. A policy of modal shift to public transport not only leads to reduce space consumption in urban areas and regained public spaces for the citizens but also to reduced emissions.

\section{CONCLUSION}

Traffic pollution impacts public health, as well as the environment. This study found that respondents were aware of the problem of traffic pollution in Kuala Lumpur. They have identified that traffic pollution is influenced by physical factors, such as 'emissions from the exhaust', and non-physical factors, such as 'wind speed'. They also agreed that traffic pollution contributes to major illnesses such as pneumonia and asthma. Most of the respondents were favourable to policies and strategies that give incentives to public transport users and also to increase the use of greener vehicle such as hybrid and electric vehicles. The findings of this study should, therefore, be taken into account by the relevant authorities in formulating policies and measures to mitigate traffic pollution in Kuala Lumpur.

\section{ACKNOWLEDGEMENTS}

The authors gratefully acknowledge the anonymous reviewers whose comments have helped in improving this paper, and also to respondents for their active participation in answering the questionnaire. 


\section{REFERENCES}

Alvinsyah, Soehodho, S., \& Nainggolan, P. J. (2005). Public transport user attitude based on choice model parameter characteristics (Case study: Jakarta busway system). Journal of the Eastern Asia Society for Transportation Studies, 6, 480-491.

Badland, H. M., \& Duncan, M. J. (2009). Perceptions of air pollution during the workrelated commute by adults in Queensland, Australia. Atmospheric Environment, 43, 5791-5795

Bayer-Oglesby, L., Schindler, C., Hazenkamp-von Arx, M. E., Braun-Fahrländer, C., Keidel, D., ... \& the SAPALDIA Team. (2006). Living near main streets and respiratory symptoms in adults the Swiss cohort study on air pollution and lung diseases in adults. American Journal of Epidemiology, 164(12), 1190-1198.

Brook, R., Franklin, B., Cascio, W., Hong, Y., Howard, G., \& Lipsett, M. (2004). Air pollution and cardiovascular disease: A statement for healthcare professionals from the expert panel on population and prevention science of the American heart association. Circulation, 109, 2655-2671.

Byrd, T. L., VanDerslice, J., \& Peterson, S. K. (1997). Variation in environmental risk perceptions and information sources among three communities in El Paso risk. Health, Safety and Environment, 8, 355-372.

Chang, H. L., \& Wu, S. C. (2005). Exploring the mode choice in daily travel behavior of the elderly in Taiwan. Journal of the Eastern Asia Society for Transportation Studies, 6, 1818-1832.

Chee, W. L., \& Fernandez, J. L. (2013). Factors that influence the choice of mode of transport in Penang: A preliminary analysis. Procedia - Social and Behavioral Sciences, 91, 120-127.

Chen, F., Jackson, H., \& Bina, W. F. (2009). Lung adenocarcinoma incidence rates and their relation to motor vehicle density. Cancer Epidemiology Biomarkers and Prevention, 18(3), 760-764.

Cunningham, B., Cunningham, M. A., \& Saigo, B. W. (2005). Environmental science: A global concern (8th Ed.). Boston: McGraw Hill.

Elosta, A. B., Leksono, A. S., \& Purnomo, M. (2013). People knowledge and perceptions about carbon dioxide $\left(\mathrm{CO}_{2}\right)$ air pollution in Malang caused by motor vehicles. International Refereed Journal of Engineering and Science, 2, 46-51.

Enger, E. D., \& Smith, B. F. (2000). Environmental science: A study of interrelationships (7th Ed.). Boston, Mass: McGraw-Hill.

Garshick, E., Laden, F., E. Hart, J., \& Caron, A. (2003). Residence near a major road and respiratory symptoms in U.S. veterans. Epidemiology, 14(6), 728-736.

Gatersleben, B., \& Uzzell, D. (2000). The risk perception of transport-generated air pollution. IATSS Research, 24, 30-38.

Gregory, C., Blanck, H., Gillespie, C., Maynard, L., \& Serdula, M. (2008). Perceived health risk of excess body weight among overweight and obese men and women: differences by sex. Preventive Medicine, 47, 46-52.

Halonen, J. I., Blangiardo, M., Toledano, M. B., Fecht, D., Gulliver, J., ... \& Tonne, C. (2016). Long-term exposure to traffic pollution and hospital admissions in London. Environmental Pollution, 208, 48-57. 
Siti Haslina Mohd Shafie, \& Mastura Mahmud

Public Perception On Traffic Pollution in Federal Territory of Kuala Lumpur, Malaysia

Han, X., \& Naeher, L. P. (2006). A review of traffic-related air pollution exposure assessment studies in the developing world. Environment International, 32, 106120.

Heinrich, J., \& Wichmann, H. E. (2004). Traffic related pollutants in Europe and their effect on allergic disease. Current Opinion in Allergy and Clinical Immunology, 4(5), 341-348.

Katsoulis, M., Dimakopoulou, K., Pedeli, X., Trichopoulos, D., Gryparis, A., Trichopoulou, A., \& Katsouyanni, K. (2014). Long-term exposure to trafficrelated air pollution and cardiovascular health in a Greek cohort study. Science of the Total Environment, 490, 934-940.

Künzli, N., Kaiser, R., Medina, S., Studnicka, M., Chanel, O., ... \& Sommer, H. (2000). Public-health impact of outdoor and traffic-related air pollution: A European assessment. Lancet, 356(9232), 795-801.

Mabahwi, N. A., Ling, O. H. L., \& Omar, D. (2015). Urban air quality and human health effects in Selangor, Malaysia. Asian Conference on Environment-Behaviour Studies, August 25-27, 2014.

Mahmud, M. (2013). Assessment of atmospheric impacts of biomass open burning in Kalimantan, Borneo during 2004. Atmospheric Environment, 78, 242-249.

Morikawa, T., Dissanayake, D., Sanko, N., Kurauchi, S.,... \& Rivera, M. (2003). Travel behavior analysis and its implication to urban transport planning for Asian cities: Case Studies of Bangkok, Kuala Lumpur, Manila, and Nagoya. Research Project, International Cooperative Research Activity (ICRA). Japan: Nagoya University

Pope, C., \& Dockery, D. (2006). Health effects of fine particulate air pollution: Lines that connect. Journal of Air and Waste Management, 56, 709-742.

Tonne, C., Beevers, S., Armstrong, B., Kelly, F., \& Wilkinson, P. (2008). Air pollution and mortality benefits of the London congestion charge: Spatial and socioeconomic inequalities. Occupational and Environmental Medicine, 65(9), 620-627.

World Health Organization (2000). Transport, environment and health. WHO Regional Publications, European Series, No. 89. 